\title{
Friction coefficient mapping using the atomic force microscope
}

\author{
S. Breakspear, J. R. Smith, ${ }^{*}$ T. G. Nevell and J. Tsibouklis \\ School of Pharmacy and Biomedical Sciences, University of Portsmouth, St. Michael's Building, White Swan Road, Portsmouth PO1 2DT, UK
}

Received 25 February 2004; Revised 5 April 2004; Accepted 15 April 2004

\begin{abstract}
A friction coefficient map of the surface of an immiscible polymer blend has been constructed using data obtained with the atomic force microscope. Spatially resolved friction coefficients, obtained from gradients of linear plots of frictional force versus applied load, were used to construct the map, with corresponding frictional forces being derived from lateral force data and the lateral spring constant. Values of the friction coefficient were confirmed using an $\mathrm{Si}_{3} \mathrm{~N}_{4} / \mathrm{Si}_{3} \mathrm{~N}_{4}$ couple, for which literature values were available. Excellent agreement with the literature was observed through the use of this method. Copyright (c) 2004 John Wiley \& Sons, Ltd.
\end{abstract}

KEYWORDS: atomic force microscopy; AFM; lateral force microscopy; LFM; friction coefficient mapping; polymer blends

\section{INTRODUCTION}

The study of the atomic-level contributors to frictional forces has been made possible through the advent of lateral force microscopy (LFM): interactions between a surface and the sliding tip are resolved from measurement of the lateral twisting motion of the atomic force microscopy (AFM) cantilever. ${ }^{1}$ The technique has been applied to the study of a wide range of systems, including: single crystals, ${ }^{2}$ alkanethiols on gold, ${ }^{3}$ conducting polymers, ${ }^{4,5}$ polyurethanes $^{6}$ and biological surfaces. ${ }^{7}$

Qualitative friction data may be obtained by subtracting the lateral force reverse trace from the forward trace. For quantification, the lateral spring constant $\left(k_{L}\right)$ of the cantilever, which is dependent on its dimensions, must be determined. ${ }^{8}$ This determination is complicated by the sensitivity of the measurement to the position of the laser spot on the cantilever surface. Hence, it is usual to obtain $k_{L}$ by indirect measurement: the 'wedge method' is one such approach. ${ }^{9}$ This procedure determines $k_{L}$ in terms of the normal spring constant, $k_{N}$, by separating the vertical (topographical) contribution to the lateral force signal from the lateral (frictional) twisting of the cantilever; lateral force measurements are made on two inclined surfaces with different slopes. The value of $k_{N}$ may be determined from measured changes in resonant frequency following the attachment of known end-masses. ${ }^{10}$

Continuing our work in the development of AFM mapping techniques to chart the heterogeneity of polymer surfaces, ${ }^{11,12}$ we now report the first example of friction coefficient mapping. For surfaces that obey Amonton's First

*Correspondence to: J. R. Smith, Scanning Probe Microscopy Laboratory, School of Pharmacy and Biomedical Sciences,

University of Portsmouth, St Michael's Building, White Swan Rd,

Portsmouth PO1 2DT, UK. E-mail: james.smith@port.ac.uk

Contract/grant sponsor: EPSRC.
Law of friction, ${ }^{13}$ coefficients of friction $(\mu)$ can be obtained from the gradient of a plot of frictional force $\left(F_{f}\right)$ versus applied load $\left(F_{N}\right)$, according to

$$
F_{f}=\mu\left(F_{N}+F_{a}\right)
$$

where $F_{a}$ is the force of adhesion.

The focus of our investigations is a system for which phase separation has been studied in considerable detail, namely: the binary polymer blend of $1: 1$ poly(methyl methacrylate) (PMMA) and poly(styrene) (PS). ${ }^{14-18}$ This system represents a well-known reference material for which the micron-scale domains of surface heterogeneity have been subjected previously to frictional-force microscopic investigations; these provide a basis for the development and evaluation of the new technique. ${ }^{17,19}$

\section{MATERIALS AND METHODS}

\section{Materials}

The PMMA (average $M_{\mathrm{w}}=28 \times 10^{4}$; polydispersity index $(\mathrm{PDI})=2.1$ ) and PS (average $M_{\mathrm{w}}=35 \times 10^{4}$; PDI $=2.0$ ) were used as obtained (Goodfellow, Cambridge, UK). Glass transition temperatures, as determined by differential scanning calorimetry, were $106^{\circ} \mathrm{C}$ and $111^{\circ} \mathrm{C}$ for PS and PMMA, respectively. Polymer blend solutions were achieved by stirring solutions $\left(2.5 \% \mathrm{w} / \mathrm{w} \mathrm{CHCl}_{3}\right)$ of the homopolymers in the desired proportion $(1: 1 \mathrm{w} / \mathrm{w})$. Films of the polymer blend were deposited onto glass substrates $(8 \mathrm{~mm} \times 8 \mathrm{~mm} \times 1 \mathrm{~mm})$ by immersion (dipping speed $=$ $1 \mathrm{~mm} \mathrm{~s}^{-1}$ ) after mixing. The resultant films were allowed to stand at room temperature (ambient conditions, dust-free environment) and rinsed with ethanol (Analar grade from $\mathrm{BDH})$ prior to AFM investigation. 


\section{Atomic force microscopy studies}

A TopoMetrix TMX2000 Discoverer scanning probe microscope (Veeco Instruments, Cambridge, UK) was used to obtain topography, lateral force images, surface roughness and force versus distance curves; the latter were carried out in water (18 M $\Omega, 0.2 \mu \mathrm{m}$ filtered; Sigma-Aldrich, Poole, UK) to overcome the effects of capillary forces between the tip and the surfaces of interest. ${ }^{11}$ For LFM studies, 'V'-shaped silicon nitride $\left(\mathrm{Si}_{3} \mathrm{~N}_{4}\right)$ cantilevers $(L=100 \mu \mathrm{m}$; experimentally determined ${ }^{10,12,20} k_{N}=0.20 \mathrm{~N} \mathrm{~m}^{-1}$ ) bearing an integrated standard profile tip (Part. No. 1530-00; ThermoMicroscopes, Santa Clara, CA, USA) were used. For adhesion measurements, $\mathrm{V}$-shaped $\mathrm{Si}_{3} \mathrm{~N}_{4}$ cantilevers $\left(L=200 \mu \mathrm{m} ; k_{N}=0.032 \mathrm{~N} \mathrm{~m}^{-1}\right.$ ) were used. The normal spring constant $\left(k_{N}\right)$ for the cantilever used in these experiments was determined by measuring the resonant frequency before and after attachment of a known end-mass. ${ }^{12}$

\section{RESULTS AND DISCUSSION}

It has been suggested that spin-cast films of mixed polymer systems may not be equilibrated thermodynamically owing to rapid solvent evaporation during the spin-casting process, ${ }^{21}$ therefore the PMMA-PS films used in the current study were deposited by dipping rather than by spinning. Although considerably thicker (310-580 nm), the films used for this study exhibited similar surface topography to the spin-cast films (1:1 PMMA-PS; 1\% w/v chloroform solution; film thickness ${ }^{22}=30-40 \mathrm{~nm}$ ) studied previously by Ton-That et al. ${ }^{17}$

Topographical and lateral force imaging (resolution $=$ $500 \times 500$ pixels; scan rate $=3 \mathrm{~Hz}$ ) were performed in contact mode in air under ambient conditions. ${ }^{20,23}$ The scan direction was perpendicular to the long axis of the cantilever to allow maximal lateral displacement for enhanced sensitivity. The thickness of the polymer blend was measured by introducing a small scratch on the surface and acquiring a contact mode AFM image at the stepedge (Fig. 1); line profile analysis was used to measure the vertical distances between the smooth, flat glass substrate and the plateaux of the PMMA $\left(R_{\mathrm{a}}=1.6 \mathrm{~nm}\right)$ and PS $\left(R_{\mathrm{a}}=1.2 \mathrm{~nm}\right)$ regions. The large difference in adhesion values obtained between PMMA-rich and PS-rich domains ( 3.2 and $0.2 \mathrm{nN}$, respectively) indicated that the films were formed by complete de-wetting of the PS underlayer and hence with exposure of phase-separated PMMA and PS regions at the surface of the blend. ${ }^{17}$ The higher force of adhesion between the $\mathrm{Si}_{3} \mathrm{~N}_{4}$ tip and the PS regions in water is indicative of the more hydrophobic character of PS. ${ }^{24,25}$

Frictional forces, $F_{f}(\mathrm{nN})$, were obtained from LFM data using a modification of the wedge method. ${ }^{9}$ Two aluminium-coated ruled diffraction gratings $(12.7 \mathrm{~mm} \times$ $12.7 \mathrm{~mm} \times 9.5 \mathrm{~mm}$; blaze angles of $4^{\circ} 18^{\prime}$ and $6^{\circ} 53^{\prime}$; Edmund Optics Ltd, York, UK) were used: only shallow slopes of each grating were accessible to the AFM tip; contact of the side of the tip with the steeper faces gave rise to artefacts.

The grating was positioned on the scanner such that the rules were perpendicular to the scan direction. For each grating, the applied load $\left(F_{N}\right)$ was calculated from the signal prior to contact $\left(I_{0}\right)$, the set point current $\left(I_{S}\right)$ and the sensor response $(S)$ as follows

$$
F_{N}=\frac{I_{s}-I_{0}}{S} k_{N}
$$

Topography and LFM images were acquired simultaneously for both the forward and reverse directions over the same area of the grating. The applied load $F_{N}$ was changed by altering $I_{s}$ in $5 \mathrm{nA}$ increments over the range $-20 \mathrm{nA}$ to $+25 \mathrm{nA}$. This change was effected after every 50 line scans. The current signal prior to contact was typically $-25 \mathrm{nA}$ and the baseline drift was found to be negligible. A Windowsbased program coded in Visual Basic was used to calculate $F_{N}$ (in $\mathrm{nN}$ ) for each corresponding $I_{s}$ step change.

Following Ogletree et al., ${ }^{9}$ a calibration plot of the lateral force current signal versus $F_{N}$ (Fig. 2) allowed the topography and friction components of the lateral force signal to be resolved. The force component on the slope that mimics $F_{f}$ can be obtained from $F_{N}$ and the slope $(\theta)$ as follows

$$
F_{f}=F_{N} \tan \theta
$$

In the Ogletree et al. paper, ${ }^{9}$ simply rotating the sample by $180^{\circ}$ could access the two different slopes. The lateral force calibration factor for a given load $(\alpha)$ using half of the difference between the lateral force signals for forward scans
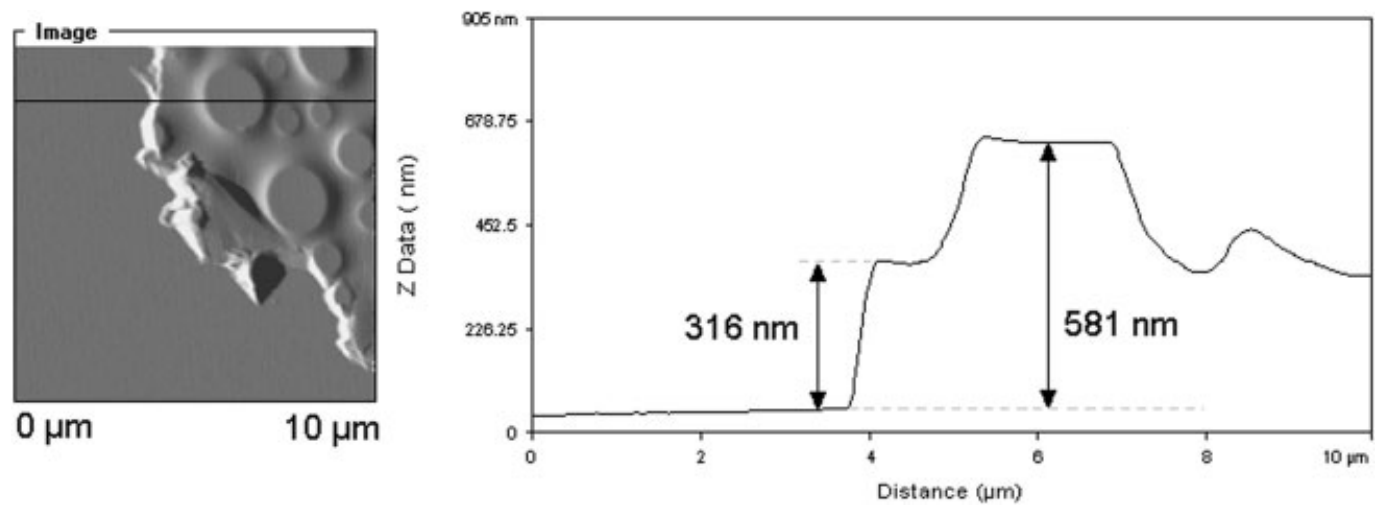

Figure 1. Typical contact-mode AFM topography image of the $1: 1$ PMMA-PS film system (the uncoated glass substrate is featureless) and the corresponding surface roughness profile; the profiled topographic line is marked across the topographic image. Thickness of PMMA-rich region $=581 \mathrm{~nm}$; thickness of PS-rich region $=316 \mathrm{~nm}$. 


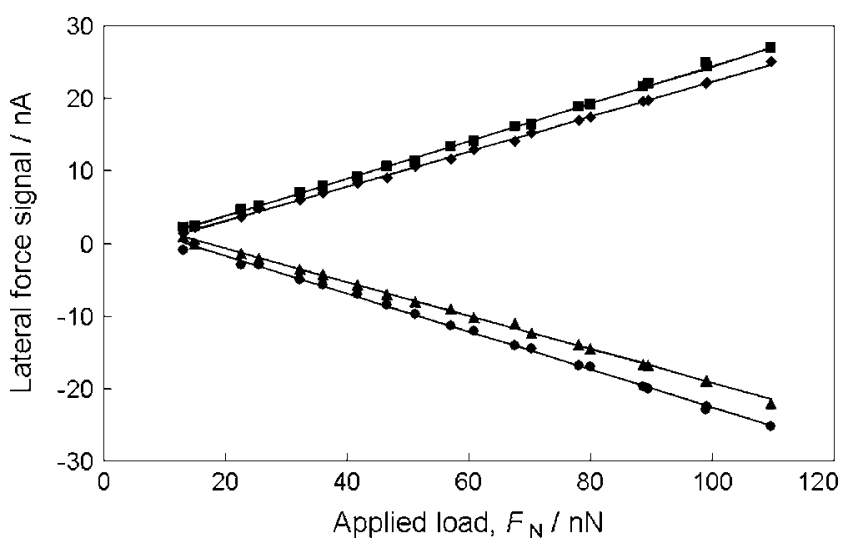

Figure 2. Calibration plot of lateral force current signal versus applied load $\left(F_{N}\right)$ used to determine $\alpha$ of the cantilever $\left(k_{N}=0.20 \mathrm{~N} \mathrm{~m}^{-1}\right)$. Lateral force signals for forward and reverse scans of diffraction gratings: forward, $4^{\circ} 18^{\prime}(\square)$ and $6^{\circ}$ $53^{\prime}(\diamond)$; reverse, $6^{\circ} 53^{\prime}(\Delta)$ and $4^{\circ} 18^{\prime}(\bullet)$.

using the two slopes $(\Delta)$ therefore could be obtained using the following equation.

$$
\alpha=\frac{F_{N} \tan \theta}{\Delta}
$$

Because the two slopes (positive and negative, $\theta_{1}$ and $\theta_{2}$ ) of interest in this work are obtained from two diffraction gratings, owing to the inaccessibility of the steeper face, $\alpha$ can be determined as follows

$$
\alpha=\frac{\tan \theta_{1}+\tan \theta_{2}}{2 \Delta} \cdot F_{N}
$$

The LFM data in the forward and reverse directions were obtained for the 1:1 PMMA-PS blend. Instead of stepping the applied load after every 50 line scans, however, a single applied load was used for each data set. This procedure was repeated for a further four applied loads in the response range -20 to $+25 \mathrm{nA}$. The applied load was incremented between scans by changing the set-point current without retracting the tip. For each applied load, the frictional force acting upon the sample at each pixel position was calculated from the difference between the forward $\left(I_{f}\right)$ and reverse $\left(I_{r}\right)$ lateral force currents, according to

$$
F_{f}=\alpha\left(I_{f}-I_{r}\right)
$$

It was observed frequently that the five topography (and corresponding lateral force) images did not overlap perfectly; this offset may have been due to some non-linearity in the response of the piezo-electric scanner. An offset between the forward and reverse images was also noted, although this can be attributed to asymmetry in the location of the AFM tip on the cantilever (Fig. 3). To compensate for this, the images were overlaid - using image processing software and custom in-house programs - to define the overlapped area of interest, to extract the frictional force data and finally to construct the friction coefficient map.

Figure 4 shows the variation in $F_{f}$ versus $F_{N}$ for the PMMA-rich and PS-rich regions of the polymer blend. Averaged values of $F_{f}$ were obtained from a matrix of single-point measurements $(N=756$ for PMMA; $N=546$

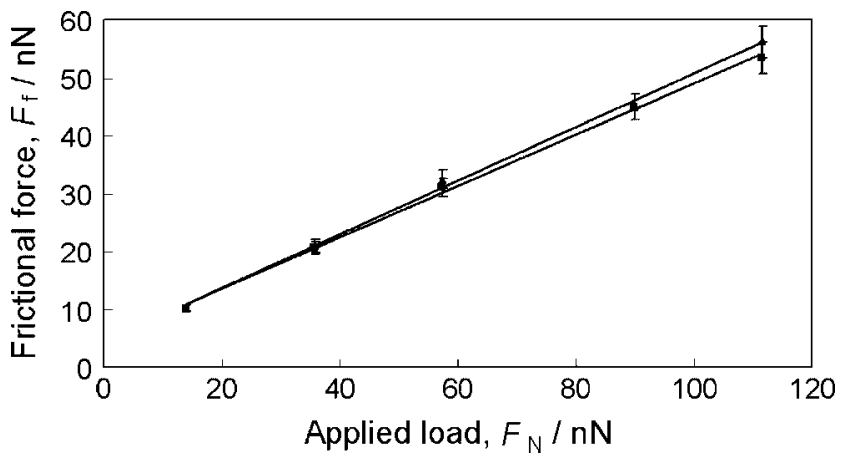

Figure 4. Plot of frictional force $\left(F_{f}\right)$ versus applied load $\left(F_{N}\right)$ for PMMA $(\boldsymbol{\square})$ and PS $(\boldsymbol{\Delta})$ regions. The gradients correspond to the friction coefficients $(\mu)$ for the different polymer phases (PMMA: 0.437; PS: 0.458). The plots do not pass through the origin due to forces arising from associated adhesion components. ${ }^{15}$

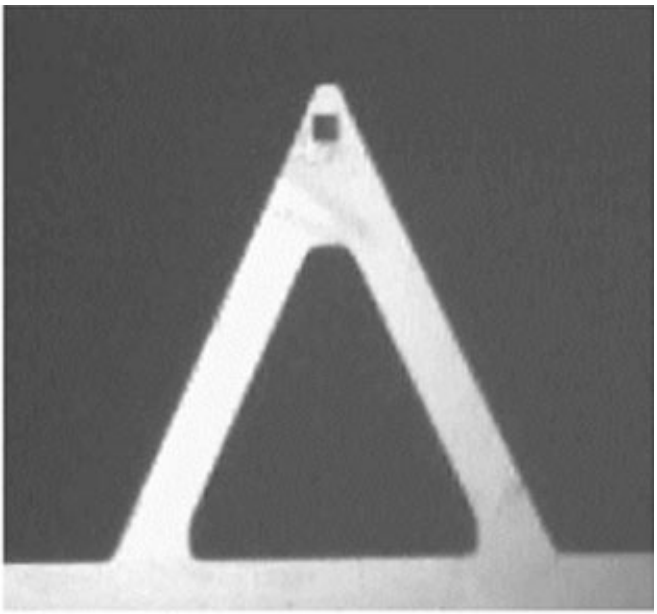

(b)

(a)

Figure 3. (a) Overlayed forward and reverse AFM topography images of a PMMA-PS polymer blend (scan range $=10 \times 10 \mu \mathrm{m}^{2}$, $z=212 \mathrm{~nm}$ ). (b) The offset in the images is due to the asymmetric location of the tip on the cantilever (length of cantilever $=100 \mu \mathrm{m}$ ). 

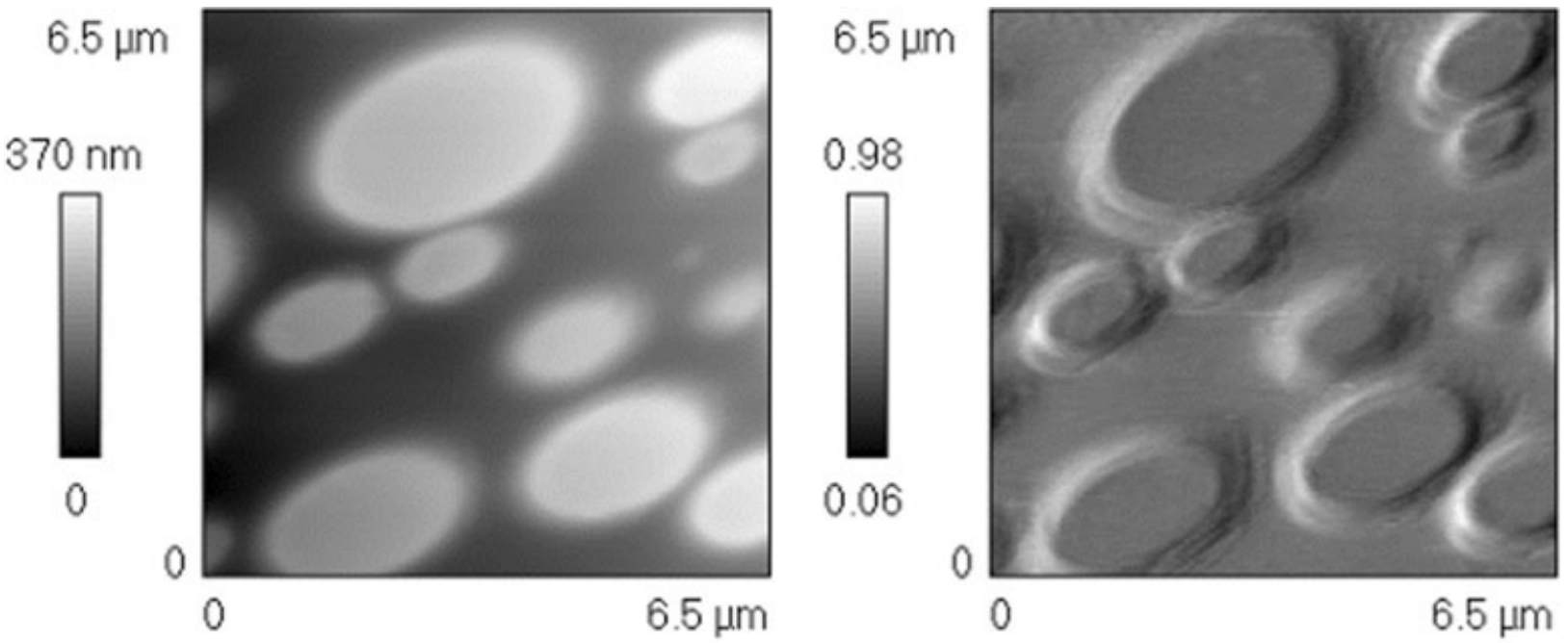

Figure 5. Topography (left) and friction coefficient map (right) of a typical PMMA-PS polymer blend surface.

for PS) using a series of applied loads; this approach was adopted because single-point measurements may not be representative of the entire domain. The linearity in each plot confirms that, up to the maximum values of $F_{N}$ investigated, both phases of the polymer obey Amonton's Law and hence $\mu$ values may be obtained directly from the gradients. The friction coefficients of PMMA and PS were found to be $0.437(\mathrm{SD}=0.013, N=2303)$ and $0.458(\mathrm{SD}=0.011$, $N=1440)$, respectively; the small difference was significant at the $P<0.05$ level $(F=2554)$. Literature values of friction coefficients (PMMA: 0.25-0.50; PS: $0.33-0.50)^{26}$ and surface energies (PMMA: $40.2 \mathrm{~mJ} \mathrm{~m}^{-2}$; PS: $41.2 \mathrm{~mJ} \mathrm{~m}^{-2}$ ) ${ }^{16}$ are also very similar for the two materials. By plotting the $\mu$ values obtained for each point of measurement within the overlapped image area, it was possible to construct a friction coefficient map (Fig. 5).

The absence of contrast between the PMMA-rich domains (high regions in the topography image ${ }^{17}$ ) and the PS-rich areas confirms that $\mu$ varies only slightly across the plateau regions of each phase. Bright and dark regions are evident at the boundaries between the two phases. These are due to the gross twisting of the cantilever as it traverses the very steep sidewalls of the PMMA-rich domains. The direction of bending of the cantilever is in opposite directions as it moves up and down these tall features, thus causing the bright and dark regions in the friction coefficient image. Such artefacts are common in all AFM experiments and are not a problem specific to the technique described here.

The friction coefficient of a surface is also dependent on the slider material. ${ }^{26}$ Because coefficients of friction for PMMA and PS against $\mathrm{Si}_{3} \mathrm{~N}_{4}$ have not been reported, it was necessary to test a known sample/slider combination to investigate whether $\mu$ values determined using the method described in this paper differed significantly from those obtained using conventional macroscopic methods. Because the AFM tip material was $\mathrm{Si}_{3} \mathrm{~N}_{4}$, mating this with an $\mathrm{Si}_{3} \mathrm{~N}_{4}$ sample provided a sample/slider couple for which literature values $(\mu=0.2-0.5)$ are available for comparison. ${ }^{13}$ The range of friction coefficient values obtained for this couple was 0.28-0.56 (mean $\mu=0.35$; $\mathrm{SD}=0.05)$, in good agreement with the literature ${ }^{13}$ and suggesting that the method used to determine friction coefficient in this paper provides equivalent values to those obtained using established macroscopic techniques. The $\mathrm{Si}_{3} \mathrm{~N}_{4}$ surfaces are known to oxidize rapidly in air to form thin layers of silicon oxides; angle-resolved XPS measurements have shown these to be $\sim 2 \mathrm{~nm}$ thick. ${ }^{27}$ Indeed, the removal and subsequent regeneration of oxide layers is considered to be the wear mechanism of $\mathrm{Si}_{3} \mathrm{~N}_{4}$ AFM tips. ${ }^{28}$ Thus, the AFM tip, the $\mathrm{Si}_{3} \mathrm{~N}_{4}$ reference sample and the literature $\mathrm{Si}_{3} \mathrm{~N}_{4} / \mathrm{Si}_{3} \mathrm{~N}_{4}$ couple are all very likely to be coated with a layer of $\mathrm{SiO}_{2}$. Of course, the importance for this paper is that the calibration sample shows the same friction coefficient as the literature reference sample, which has been demonstrated. The universal applicability of this technique, however, remains to be tested through consideration of other immiscible blend systems, the polymeric components of which exhibit a greater variation in surface free energy and friction coefficient.

\section{CONCLUSIONS}

This paper describes a new development in LFM: friction coefficient mapping. The technique, which was validated using an $\mathrm{Si}_{3} \mathrm{~N}_{4} / \mathrm{Si}_{3} \mathrm{~N}_{4}$ sample/slider couple, has been employed to map the surface of a PMMA-PS polymer blend.

\section{Acknowledgements}

We thank Dr Robert Jones at the University of Lancaster for helpful discussions and the EPSRC for supporting this work.

\section{REFERENCES}

1. Baselt DR, Baldeschwieler JD. J. Vac. Sci. Technol. B 1992; 10: 2316.

2. Polaczyk C, Schneider T, Schöfer J, Santner E. Surf. Sci. 1998; 402-404: 454

3. Barrena E, Ocal C, Salmeron M. Surf. Sci. 2001; 482-485: 1216.

4. Liu X, Chetwynd DG, Gardner JW, Bartlett PN, Beriet C. Tribol. Int. 1998; 31: 313.

5. Levi MD, Cohen Y, Aurbach D, Lapkowski M, Vieil E, Serose J. Synth. Met. 2000; 109: 55.

6. Sidouni F-Z, Nurdin N, Chabrecek P, Lohmann D, Vogt J, Xanthopoulos N, Mathieu HJ, Francois P, Vandaux P, Descouts P. Surf. Sci. 2001; 491: 355. 
7. Smith JR, Swift JA. J. Microsc. 2002; 206: 182

8. Bogdanovic G, Meurk A, Rutland MW. Colloids Surf. B 2000; 19: 397.

9. Ogletree DF, Carpick RW, Salmeron M. Rev. Sci. Instrum. 1996; 67: 3298 .

10. Cleveland JP, Manne S, Bocek D, Hansma PK. Rev. Sci. Instrum. 1993; 64: 403.

11. Eaton P, Graham P, Smith JR, Smart JD, Nevell TG, Tsibouklis J. Langmuir 2000; 16: 7887.

12. Eaton P, Smith JR, Graham P, Smart JD, Nevell TG, Tsibouklis J. Langmuir 2002; 18: 3387.

13. Bhushan B. Principles and Applications of Tribology (1st edn). John Wiley: New York, 1992.

14. Kressler J, Higashida N, Inoue T, Heckmann W, Seitz F. Macromolecules 1993; 26: 2090.

15. Kressler J, Higashida N, Shimomai K, Inoue T, Ougizawa T. Macromolecules 1994; 27: 2448.

16. Tanaka K, Takahara A, Kajiyama T. Macromolecules 1996; 29: 3232
17. Ton-That C, Shard AG, Teare DOH, Bradley RH. Polymer 2001; 42: 1121.

18. Lipatov YS, Prog. Polym. Sci. 2002; 27: 1721

19. Krausch G, Hipp M, Boltau M, Marti O, Mlynek J. Macromolecules 1995; 28: 260.

20. Tsibouklis J, Graham P, Eaton P, Smith JR, Nevell TG, Smart JD, Ewen RJ. Macromolecules 2000; 33: 8460.

21. Garbassi F, Morra M, Occhiello E. Polymer Surfaces: from Physics to Technology. John Wiley: Chichester, 1998; p. 291.

22. Ton-That C, Shard AG, Bradley RH. Langmuir 2000; 16: 2281.

23. Gulbinski W, Pailharey D, Suszko T, Mathey Y. Surf. Sci. 2001; 475: 149.

24. Cappella B, Dietler G. Surf. Sci. Rep. 1999; 34: 1.

25. Cappella B, Sturm H, Weidner SM. Polymer 2002; 43: 4461.

26. Hall C. Polymer Materials. An Introduction for Technologists and Scientists (2nd edn). Max Milian: London, 1989; p. 86.

27. Hah SR, Burk CB, Fischer TE. J. Electrochem. Soc. 1999; 146: 1505.

28. Maw W, Stevens F, Langford SC, Dickinson JT. J. Appl. Phys. 2002; 92: 5103 